\title{
Kinetics of dissociative chemisorption of methane and ethane on $\mathrm{Pt}(110)-(1 \times 2)$
}

\author{
Y.-K. Sun ${ }^{a)}$ \\ Division of Chemistry and Chemical Engineering, California Institute of Technology, Pasadena, California \\ 91125 \\ W.H. Weinberg \\ Department of Chemical Engineering, University of California, Santa Barbara, California 93106
}

(Received 25 August 1989; accepted 30 October 1989)

\begin{abstract}
The initial probability of dissociative chemisorption $P_{r}$ of methane and ethane on the highly corrugated, reconstructed $\mathrm{Pt}(110)-(1 \times 2)$ surface has been measured in a microreactor by counting the number of carbon atoms on the surface following the reaction of methane and ethane on the surface which was held at various constant temperatures between 450 and $900 \mathrm{~K}$ during the reaction. Methane dissociatively chemisorbs on the $\mathrm{Pt}(110)-(1 \times 2)$ surface with an apparent activation energy of $14.4 \mathrm{kcal} / \mathrm{mol}$ and an apparent preexponential factor of 0.6 . Ethane chemisorbs dissociatively with an apparent activation energy of $2.8 \mathrm{kcal} / \mathrm{mol}$ and an apparent preexponential factor of $4.7 \times 10^{-3}$. Kinetic isotope effects were observed for both reactions. The fact that $P_{r}$ is a strong function of surface temperature implies that the dissociation reactions proceed via a trapping-mediated mechanism. A model based on a trapping-mediated mechanism is used to explain the observed kinetic behavior. Kinetic parameters for $\mathrm{C}-\mathrm{H}$ bond dissociation of the thermally accommodated methane and ethane are extracted from the model.
\end{abstract}

\section{INTRODUCTION}

The dissociative chemisorption of a gas-phase molecule on a solid surface is a complicated process that occurs on a multidimensional potential energy surface. The mechanisms by which a gas molecule dissociatively chemisorbs on a surface are often classified into two types, namely, trapping-mediated and direct mechanisms. ${ }^{1-5}$ In the trapping-mediated mechanism, the gas molecules lose a sufficient fraction of their incident kinetic energy to become trapped and thermally accommodated to the surface temperature. The trapped molecules can either desorb back into gas phase, or they can locate a minimum barrier in the potential energy surface and chemisorb. In the case of methane and ethane on the Pt (110)-(1×2) surface, the trapped molecules may be considered to be physically adsorbed, and the chemisorption is dissociative involving $\mathrm{C}-\mathrm{H}$ bond cleavage. The observed probability of dissociative chemisorption is a convolution of a dynamical factor (the trapping probability) and a kinetic factor (the relative rates of dissociation versus desorption from the physically adsorbed state). The former decreases precipitously with increasing incident translational energy (or gas "temperature") ) $^{5,6}$ but is a rather weak function of the surface temperature. ${ }^{4}$ The latter can be rather sensitive to the surface temperature, depending upon the energetics associated with the two competing pathways for the trapped molecules. ${ }^{2}$ The rate associated with the direct mechanism, however, is not a strong function of the surface temperature. The overall rate of dissociative chemisorption can be expressed as the sum of a trapping-mediated component and a direct component. Depending upon the reaction conditions, one of the two components may be dominant in the overall rate, making it possible to investigate the kinetics and dy. namics of the two reaction channels separately. This has been demonstrated explicitly for the dissociative chemisorp- tion of nitrogen on the W(100) surface ${ }^{4}$ and ethane on the $\operatorname{Ir}(110)-(1 \times 2)$ surface. 5

The activation of $\mathrm{C}-\mathrm{H}$ bonds in alkanes for subsequent functionalization is an extremely important chemical process. An understanding of the chemical interactions of methane and ethane, the two simplest alkanes, with initially clean transition metal surfaces is likewise very important. While there have been a number of molecular beam investigations of the direct, dissociative chemisorption of methane on a variety of transition metal surfaces including $\mathrm{W}(110){ }^{7}$ $\operatorname{Ir}(110)-(1 \times 2),{ }^{8,9} \quad \operatorname{Pt}(111),{ }^{10,11} \quad \mathrm{Ni}(111),{ }^{12}$ and Ni(110), ${ }^{1.3}$ less work has been concerned with dissociative chemisorption on well-characterized surfaces via the trapping-mediated mechanism. ${ }^{14,85}$ The goal of the work reported here is to measure the probability of dissociative chemisorption of methane and ethane via the trapping-mediated mechanism and to interpret the results microscopically.

\section{EXPERIMENTAL DETAILS}

The experiments were performed in a microreactor that has been described previously. ${ }^{16,17}$ The microreactor has a volume of $30 \mathrm{~cm}^{3}$ and is connected to an ion-pumped ultrahigh vacuum (UHV) chamber which has a base pressure of $3 \times 10^{-10}$ Torr. The reactant pressures were measured by a Baratron gauge. Both sides of the Pt (110) crystal were polished and the surfaces were cleaned initially by argon ion sputtering in situ in the microreactor. The (110) surface has a total area of $0.8 \mathrm{~cm}^{2}$ (both sides). Two high purity platinum wires (0.010 in. diameter and $0.2 \mathrm{in}$. length) were spot welded to the edge of the crystal and were clamped onto two 0.24-cm-diam copper leads that support the crystal and allow it to be heated resistively. The temperature of the crystal was measured with a 0.003 -in.-diam W-5\% $\operatorname{Re} / W-26 \% \operatorname{Re}$ 
thermocouple, which was spot welded to the crystal. The crystal was cleaned between experiments by heating to 950 $\mathrm{K}$ for $5 \mathrm{~min}$ in $5 \times 10^{4}$ Torr of $\mathrm{O}_{2}$ flowing through the microreactor, and subsequently in $5 \times 10^{-4}$ Torr of $\mathrm{H}_{2}$ for another $5 \mathrm{~min}$ to remove surface oxygen. Thermal desorption spectra of $\mathrm{CO}$ from the surface are in good agreement with the previously published ones, ${ }^{18}$ verifying the validity of our cleaning procedures.

The microreactor was operated in a batch mode when studying the dissociation of methane $\left({ }^{13} \mathrm{CH}_{4}\right)$ on $\mathrm{Pt}(110)$ $(1 \times 2)$ at low surface temperatures $(\leqslant 740 \mathrm{~K})$, since the probability of dissociative chemisorption is very low. In this mode the crystal was held at a constant temperature, and a methane "pressure jump" was created by rapidly opening and then closing the inlet valve. The transient part of the pressure profile is shorter than five seconds, which is less than $15 \%$ of the minimum batch reaction time. Thus we have a well-defined reaction condition (i.e., surface temperature and reactant pressure). The methane was allowed to react in the sealed reactor for a period of time $\tau$, followed by immediate cooling of the crystal and pump-out of the contents of the reactor. The number of carbon- 13 adatoms on the surface $N_{c}$, which is directly proportional to the probability of dissociation, was determined by counting the number of ${ }^{13} \mathrm{CO}_{2}$ molecules mass spectrometrically during oxygen titration of the carbon-13 adatoms. During the oxygen titration, the surface was heated to and held at $550 \mathrm{~K}$ in vacuum, oxygen was then introduced into the reactor, and the mass spectrometric intensity of ${ }^{13} \mathrm{CO}_{2}$ was recorded. No ${ }^{13} \mathrm{CO}$ was observed under the titration conditions. The absolute rate of production of ${ }^{13} \mathrm{CO}_{2}$ was determined by calibrating the mass spectrometer with a known leak of $\mathrm{CO}_{2}$ into the microreactor. The pressure of methane and the value of $\tau$ were chosen in a such way that the coverage of carbon- 13 adatoms is above the detection limit of the titration method and below $10 \%$ of a monolayer. The initial probability of dissociative chemisorption at a surface temperature $T, P_{r}(T)$, was calculated by extrapolation to zero-carbon coverage using the following relation:

$$
p_{r}(T)=\frac{N_{c}}{n \tau F},
$$

where $n$ is the number of carbon atoms in the reactant molecule, and $F$ is the impingement rate of reactant molecules.

For the dissociative chemisorption of methane at high surface temperatures $(>740 \mathrm{~K})$ and ethane in the entire temperature range studied ( 345 to $715 \mathrm{~K}$ ), the experimental procedure was the same as that described above except that the reactor was operated in a flow mode in which the reactant continuously flows through the reactor for a period of time $\tau$ at a fiow rate that is much greater than the reaction rate in order to maintain low conversions of methane (at a pressure of approximately $1 \times 10^{-4}$ Torr) and ethane (at a pressure of $5 \times 10^{-6}$ Torr) in the reactor. Unlabeled ethane $\left(\mathrm{C}_{2} \mathrm{H}_{6}\right)$ rather than carbon-13 labeled ethane was used since it was found in the experiments with the carbon-13 labeled methane that the signal of ${ }^{12} \mathrm{CO}_{2}$ due to oxidation of background $\mathrm{CO}$ is negligibly small compared with that of ${ }^{1.3} \mathrm{CO}_{2}$ under the titration conditions. Hence the carbon labeling was not necessary.

Both the carbon-13 labeled methane $\left({ }^{1.3} \mathrm{CH}_{4}, 99\right.$ atom $\left.\%{ }^{13} \mathrm{C}\right)$ and deuterated methane $\left(\mathrm{CD}_{4}, 99\right.$ atom $\left.\% \mathrm{D}\right)$ were obtained from Icon Services, the ethane $\left(\mathrm{C}_{2} \mathrm{H}_{6}\right.$, $99.99 \%)$ from Matheson, and the deuterated ethane $\left(C_{2} D_{6}\right.$, 98 atom \% D) from Cambridge Isotopes. All gases were manipulated in a gas manifold that was pumped by a diffusion pump and had a base pressure below $1 \times 10^{-7}$ Torr.

\section{RESULTS AND DISCUSSION}

The logarithm of the measured initial probability of dissociative chemisorption $P_{r}$ of ${ }^{13} \mathrm{CH}_{4}$ on the $\mathrm{Pt}(110)-(1 \times 2)$ surface is plotted as a function of reciprocal surface temperature in Fig. 1, where $P_{r}$ is represented by filied circles. The diagram is divided into three different regimes (by the two vertical dashed lines), i.e., low- (below $510 \mathrm{~K}$ ), intermediate- $(510$ to $740 \mathrm{~K}$ ), and high-temperature (above $740 \mathrm{~K}$ ) regimes. In the low-temperature regime, $P_{r}$ increases with increasing surface temperature more rapidly than it does in the intermediate surface temperature regime. In the hightemperature regime, $P_{r}$ first levels off and then decreases slightly with increasing surface temperature. Only in the intermediate-temperature regime is $P_{r}$ the true initial dissociative chemisorption probability of ${ }^{13} \mathrm{CH}_{4}$ on the $\mathrm{Pt}(110)$ $(1 \times 2)$ surface. In the low-temperature regime, the measured value of $P_{r}$ is decreased due to adsorption of $\mathrm{CO}$ from the background, and in the high-temperature regime it is decreased due to the diffusion of carbon into the bulk of the platinum. ${ }^{17}$ Taking into account appropriate corrections for these processes caused all data to agree with those measured at intermediate temperatures, cf. Fig. 1. The slope of the straight line in Fig. 1 corresponds to an apparent activation energy of $14.4 \mathrm{kcal} / \mathrm{mol}$ and an apparent preexponential factor of 0.6 , i.e., we find

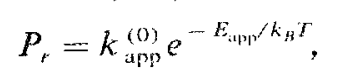

where $k_{\mathrm{app}}^{(0)}=0.6$ and $E_{\mathrm{app}}=14.4 \mathrm{kcal} / \mathrm{mol}$.

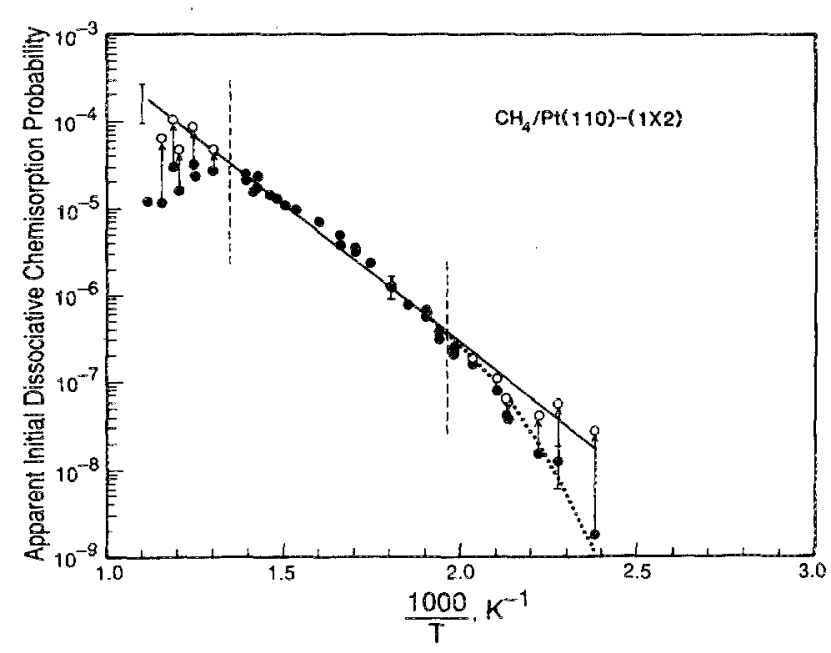

FIG. 1. Arrhenius plot of the apparent initial dissociative chemisorption probability, $P, p(O)$, of ${ }^{13} \mathrm{CH}_{4}$ on the $\mathrm{Pt}(110)-(1 \times 2)$ surface. Two vertical dashed lines divide the diagram into three different regimes. The solid line is a fit to the data in the intermediate temperature regine with $E_{\text {atp }}=14.4 \mathrm{kcal} / \mathrm{mol}$. The data at both low and high temperatures fall on this same line when suitably corrected (see the text). 
The initial probability of dissociative chemisorption of $\mathrm{CD}_{4}$ was also measured and was found to be consistently lower than that of ${ }^{13} \mathrm{CH}_{4}$. Assuming the same value of the preexponential factor as for ${ }^{1.3} \mathrm{CH}_{4}$, the apparent activation energy for the dissociative chemisorption of $\mathrm{CD}_{4}$ is 15.6 $\mathrm{kcal} / \mathrm{mol}^{17}{ }^{17}$ The observation of this kinetic isotope effect is expected since $\mathrm{C}-\mathrm{H}$ bond cleavage is the rate-limiting step in the decomposition of the methane.

Ethane dissociates on the $\mathrm{Pt}(110)-(1 \times 2)$ surface more readily than methane. The initial probability of dissociative chemisorption of $\mathrm{C}_{2} \mathrm{H}_{6}$ and $\mathrm{C}_{2} \mathrm{D}_{6}$ were measured at a pressure of $5 \times 10^{-6}$ Torr. Since the reactant pressure was much lower than it was in the methane experiment, there is negligible background adsorption of $\mathrm{CO}$ in this case. The results of the measurements are shown in Fig. 2 in the form of an Arrhenius plot. The data are well described by Eq. (2) with an apparent activation energy of $2.8 \mathrm{kcal} / \mathrm{mol}$ and an apparent preexponential factor of $4.7 \times 10^{-3}$. Deuterated ethane reacts on the surface with a rate that is approximately 2.5 times slower than that of $\mathrm{C}_{2} \mathrm{H}_{6}$, with an apparent activation energy of $3.5 \mathrm{kcal} / \mathrm{mol}$ and the same preexponential factor as that of $\mathrm{C}_{2} \mathrm{H}_{6}$.

Since anl of the experiments were carried out at reactant pressures below $10^{-2}$ Torr, the temperature of the reactants should be nearly equal to the wall temperature of the reactor (approximately $300 \mathrm{~K}$ ) rather than the surface temperature of the single crystal. ${ }^{14}$ The probability of direct, dissociative chemisorption of a Maxwell-Boltzmann gas of methane or ethane at $300 \mathrm{~K}$ is negligibly small compared to our measured values. Furthermore, the fact that $P_{r}$ is a strong function of surface temperature and can be described by Eq. (2) indicates that the dissociation reactions are proceeding via a trapping-mediated mechanism. Consider, for example, the case of methane. A trapped methane molecule can either desorb or dissociate on the surface, i.e.,

$$
\begin{aligned}
& \mathrm{CH}_{4}(\mathrm{~g}) \stackrel{\stackrel{s}{\Rightarrow}=\mathrm{CH}_{4}(\mathrm{a}),}{\mathrm{Cr}_{\mathrm{r}}} \\
& \mathrm{CH}_{4}(\mathrm{a}) \stackrel{k_{r}}{\rightarrow} \mathrm{C}(\mathrm{a})+2 \mathrm{H}_{2}(\mathrm{~g}),
\end{aligned}
$$

where (a) implies the adsorbed phase and ( $g$ ) the gap phase. Assuming a pseudo-steady-state for ${ }^{13} \mathrm{CH}_{4}$ (a), one finds that the probability of dissociation is given by Eq. (2),

$$
P_{r}=\frac{\xi k_{r}}{k_{r}+k_{d}}
$$

where $\zeta$ is a thermal average of the trapping probability of methane, and $k_{d l}$ and $k_{r}$ are the rate coefficients of the two competing processes, i.e., desorption and reaction of the trapped methane molecules on the surface. Since $k_{d} \gg k_{r}$ for methane on the $\mathrm{Pt}(110)-(1 \times 2)$ surface, Eq. (4) may be rewritten as

$$
P_{r} \simeq \xi \frac{k_{r}}{k_{d}} .
$$

Assuming that both $k_{d}$ and $k_{r}$ are of the Arrhenius form $k_{i}^{(0)} e^{-F_{i} / k_{B} T^{\prime}}$ and that $\zeta$ is independent of the surface temperature, ${ }^{4}$ one would expect a straight line when $\ln P_{r}$ is plotted versus $1 / T$ with the slope being $-\left(E_{r}-E_{d}\right) / k_{B}$

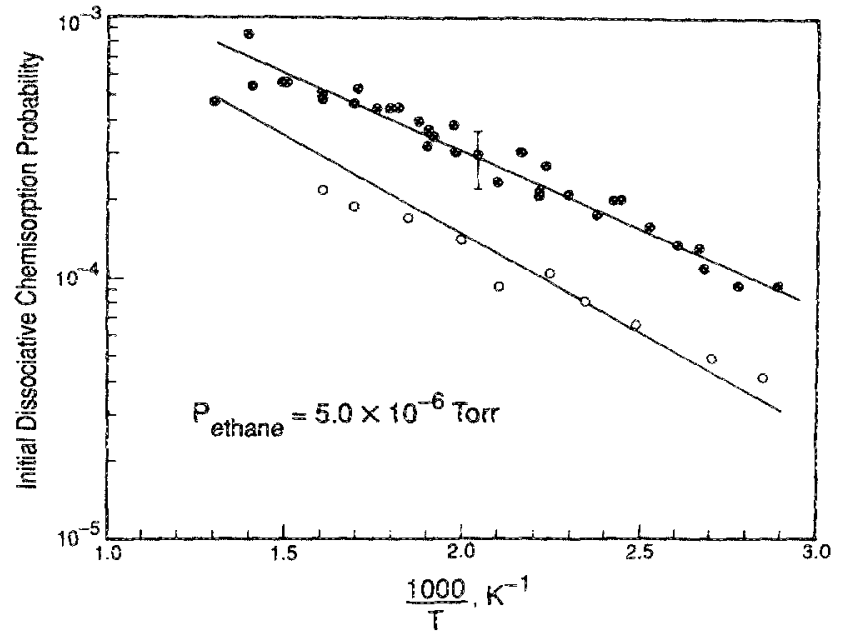

FIG. 2. Arrhenius piot of the initial dissociative chemisorption probability of $\mathrm{C}_{2} \mathrm{H}_{6}(9)$ and $\mathrm{C}_{2} \mathrm{D}_{n}(\mathrm{O})$ on $\mathrm{Pt}(110)-(1 \times 2)$. The apparent activation energies arc 2.8 and $3.5 \mathrm{kcal} / \mathrm{mol}$, respectively.

and the intercept being $\ln \left(\xi k_{r}^{(0)} / k_{d}^{(b)}\right)$. Hence, our measured apparent activation energies for the dissociative chemisorption of methane $(14.4 \mathrm{kcal} / \mathrm{mol})$ and ethane $(2.8$ $\mathrm{kcal} / \mathrm{mol}$ ) represent the activation energy with respect to an energy zero that is the alkane in the gas phase. The activation energy with respect to the bottom of the physically adsorbed well $E_{r}$ is simpiy equal to the measured activation energy plus the activation energy for desorption $E_{d}$ of the physicaily adsorbed alkane, i.e., $E_{r}=E_{\mathrm{app}}+E_{d}$. Since the values of $E_{d}$ for methane and ethane are approximately 4 and 7.5 $\mathrm{kcal} / \mathrm{mol}$, repectively, ${ }^{17}$ the values of $E_{r}$ for methane and ethane on this surface are approximately 18.4 and 10.3 $\mathrm{kcal} / \mathrm{mol}$, respectively. Furthermore, if the preexponential factors of the desorption rate coefficients of methane and ethane from the physically adsorbed well are $10^{13} \mathrm{~s}^{-1}$ and $\xi$ is taken to be unity, ${ }^{5}$ then the preexponential factors of the rate coefficients for dissociation on this surface are $6 \times 10^{i 2}$ $\mathrm{s}^{-1}$ for methane and $4.7 \times 10^{10} \mathrm{~s}^{-1}$ for ethane.

\section{SUMMARY}

The initial probabilities of dissociative chemisorption of methane and ethane on the highly corrugated, reconstructed $\operatorname{Pt}(110)-(1 \times 2)$ surface have been measured. The surface temperature was varied with the reactant gas temperature maintained constant at $300 \mathrm{~K}$. Under these conditions we probed the kinetics of trapping-mediated dissociation. Dissociative chemisorption is activated for both methane with an apparent activation energy of $14.4 \mathrm{kcal} / \mathrm{mol}$, and ethane with an apparent activation energy of $2.8 \mathrm{kcal} / \mathrm{mol}$. These activation energies are measured with respect to the alkane in the gas phase. The activation energies measured with respect to the bottom of the physically adsorbed well (i.e., the activation energies of the elementary surface reactions) are approximately $18.4 \mathrm{kcal} / \mathrm{mol}$ for methane and 10.3 $\mathrm{kcal} / \mathrm{mol}$ for ethane.

\section{ACKNOWLEDGMENTS}

This work was supported by the Office of Basic Energy Sciences of the Deparment of Energy (Grant No. DE- 
FG03-89ER 14048). Additional support was provided by the Donors of the Petroleum Research Fund of the American Chemical Society (Grant No. PRF19819-AC5-C).

a) Present address: Department of Chemistry BG-10, University of Washington, Seattle, WA 98195.

'P. Kisliuk, J. Phys. Chem. Solids 3, 95 (1957); 5, 78 (1958).

${ }^{2}$ W. H. Weinberg, in Kinetics of Interface Reactions, edited by M. Grunze and H. J. Kreuzer, (Springer, Heidelberg, 1987), p. 94.

${ }^{3}$ S. G. Brass and G. Ehriich, J. Chem. Phys. 87, 4285 (1987).

4 (a) C. T. Rettner, H. Stein, and E. H. Schweizer, J. Chem. Phys. 89, 3337 (1988) . (b) C. T. Rettner, E. H. Schweizer, H. Stein, and D. J. Auerbach, Phys. Rev. Lett. 61, 986 (1988).

${ }^{9}$ C. B. Mullins and W. H. Weinberg, J. Chem. Phys. (in press).

${ }^{6}$ C. T. Rettner, E. K. Schweizer, and C. B. Mullins, J. Chem. Phys. 90 , 3800 (1989).
${ }^{7}$ C. T. Rettner, H. E. Pfnür, and D. J. Auerbach, Phys. Rev. Lett. 25, 2716 (1985).

${ }^{8}$ A. V. Hamza, H.-P. Steinrück, and R. J. Madix, J. Chem. Phys. 86, 6506 (1987).

${ }^{9} \mathrm{C}$. B. Mullins and W.H. Weinberg (to be published).

${ }^{10}$ G. R. Schoofs, C. R. Arumainayagam, M. C. McMaster, and R. J. Madix, Surf. Sci. 215, 1 (1989).

"A. C. Luntz and D. S. Bethune, J. Chem. Phys. 90, 1274 (1989).

${ }^{12}$ M. B. Lee, Q. Y. Yang, and S. T. Ceyer, J. Chem. Phys. 87, 2724 (1987).

${ }^{13}$ A. V. Hamza and R. J. Madix, Surf. Sci, 179, 25 (1987).

${ }^{14}$ T. M. Beebe, $J_{r}$, D. W. Goodman, B. D. Kay, and J. T. Yates, Jr., J. Chem. Phys. 87, 2305 (1987).

${ }^{15}$ A. G. Sault and D. W. Goodman, J. Chem. Phys. 88, 7232 (1988).

${ }^{16}$ J. J. Vajo, W. Tsai, and W. H. Weinberg, Rev. Sci. Instrum. 56, 1439 (1985).

${ }^{17}$ Y.-K. Sun and W. H. Weinberg ( to be published).

${ }^{18}$ C. M. Comrie and R. M. Lambert, J. Chem. Soc. Faraday Trans. 172, 325 (1975). 